Magazine of Concrete Research Volume 65 Issue 10

Mechanical characteristics of selfcompacting concrete with and without fibres

Aslani and Nejadi
Magazine of Concrete Research, 2013, 65(10), 608-622 i

\title{
Mechanical characteristics of self-compacting concrete with and without fibres
}

Farhad Aslani

Centre for Built Infrastructure Research, School of Civil and Environmental Engineering, University of Technology Sydney, Australia
Shami Nejadi

Centre for Built Infrastructure Research, School of Civil and Environmental Engineering, University of Technology Sydney, Australia

Fibre-reinforced self-compacting concrete (FRSCC) is a high-performance building material that combines positive aspects of fresh properties of self-compacting concrete (SCC) with improved characteristics of hardened concrete as a result of fibre addition. Considering these properties, the application ranges of both FRSCC and SCC can be covered. A test program is carried out to develop information about the mechanical properties of FRSCC. For this purpose, four SCC mixes - plain SCC, steel, polypropylene and hybrid FRSCC - are considered in the test program. The properties include compressive and splitting tensile strengths, modulus of elasticity, modulus of rupture, and compressive stress-strain curve. These properties are tested at 3, 7, 14, 28, 56 and 91 days. Relationships are established to predict the compressive and splitting tensile strengths, modulus of elasticity, modulus of rupture, and compressive stress-strain curve. The models provide predictions matching the measurements.

\section{Introduction}

Self-compacting concrete (SCC) can be placed and compacted under its own weight with little or no vibration, and without segregation or bleeding. SCC is used to facilitate and ensure proper filling, and good structural performance of restricted areas and heavily reinforced structural members. It has gained significant importance in recent years because of its advantages. Recently, this concrete has gained wider use in many countries for different applications and structural configurations. SCC can also provide a better working environment by eliminating the vibration noise. Such concrete requires a high slump that can be achieved easily by superplasticiser addition to a concrete mix and special attention to the mix proportions. SCC often contains a large quantity of powdered materials that are required to maintain sufficient yield value and viscosity of the fresh mix, thus reducing bleeding, segregation and settlement. As the use of a large quantity of cement increases costs and results in higher temperatures, the use of additions, such as fly ash, blast furnace slag or limestone filler, could increase the slump of the concrete mix without increasing its cost (Aslani and Nejadi, 2012a, 2012b, 2012c, 2012d).

The incorporation of fibres improves engineering performance of structural and non-structural concrete. The use of fibre-reinforced concrete (FRC) is also of special interest for retrofit and seismic design. The incorporation of metallic fibres can be problematic on some situations, especially when the fibre volume is high and the FRC is cast in sections with a moderate-to-high degree of reinforcement. The fibre content, length, aspect ratio and shape play an important role in controlling workability of FRC. Such concrete presents greater difficulty in handling, and requires more deliberate planning and workmanship than established concrete construction procedures. The additional compaction effort required for such concrete contributes to the increase in construction cost. In order to provide sufficient compaction, improve fibre dispersion and reduce the risk of entrapping voids, the FRC is often proportioned to be fluid enough to reduce the need for vibration consolidation and facilitate placement. An extension of this approach can involve the use of SCC to eliminate, or greatly reduce, the need for vibration and further facilitate placement. A truly fibre-reinforced self-compacting concrete (FRSCC) should spread into place under its own weight and achieve consolidation without internal or external vibration, ensure proper dispersion of fibres, and undergo minimum entrapment of air voids and loss of homogeneity until hardening. Lack of proper self-compaction or intentional vibration and compaction can result in macro- and micro-structural defects that can affect mechanical performance and durability (Khayat and Roussel, 1999).

FRSCC is a relatively recent composite material that combines the benefits of SCC technology with the advantages of the fibre addition to a brittle cementitious matrix. It is a ductile material that, in its fresh state, flows into the interior of the formwork, filling it in a natural manner, passing through the obstacles, and flowing and consolidating under the action of its own weight. FRSCC can mitigate two opposing weaknesses: poor workability in FRC and cracking resistance in plain concrete. A few studies have been carried out on optimisation of the mix proportion for the addition of steel or polypropylene fibres to SCC. Meanwhile, there is insufficient research on the mechanical properties of FRSCC. In mechanical terms, the greatest disadvantage of cementitious material is its vulnerability to cracking, which generally occurs at an early age in concrete structures or 
members. Cracking may potentially reduce the lifetime of concrete structures, and cause serious durability and serviceability problems. The addition of fibres into SCC mixtures has been studied by a number of researchers (Bui et al., 2003; Busterud et al., 2005; Corinaldesi and Moriconi, 2004; Cunha, 2006; Groth and Nemegeer, 1999; Grünewald, 2006; Grünewald and Walraven, 2001; Khayat and Roussel, 1999; Liao et al., 2006; Massicotte et al., 2000; Sahmaran et al., 2005; Sahmaran and Yaman, 2007; Schumacher, 2008).

The most beneficial properties with fibre addition to the concrete in the hardened state are the impact strength, the toughness and the energy absorption capacity. A detailed description of the benefits provided by fibre addition to concrete can be found elsewhere (ACI 544.2R (ACI, 1999); Balaguru and Shah, 1992). The fibre addition might also improve the fire resistance of cement-based materials, as well as their shear resistance. The possible applications of FRSCC include highways; industrial and airfield pavements; hydraulic structures; tunnel segments; bridges components; and concrete structures of complex geometry that present high difficulties in being reinforced by conventional steel bars, especially those that have a high degree of support redundancy.

The research presented aims at finding the properties of SCC and FRSCC in the fresh and hardened stages. An experimental program is carried out to investigate the mechanical properties of four mixes of SCC. The mechanical properties included in this study are compressive and splitting tensile strengths, modulus of elasticity, modulus of rupture and compressive stress-strain curve. These properties are tested at 3, 7, 14, 28, 56 and 91 days. The developments of mechanical properties with time are investigated.

As only a few correlations among the mechanical properties of FRSCC have been reported and are unclear, regression analyses are conducted on existing experimental data to propose splitting tensile strength, modulus of elasticity and modulus of rupture models on compressive strength and age of concrete. Also, compressive stress-strain relationships for SCC and FRSCC are compared with the test results.

\section{Experimental study}

\section{Materials}

\section{Cement}

In this experimental study, shrinkage limited cement (SLC) corresponding to the AS 3972 (SA, 2010) standard was used. SLC is manufactured from specially prepared Portland cement clinker and gypsum. It may contain up to $5 \%$ of AS 3972approved additions. The chemical, physical and mechanical properties of the cement used in the experiments are shown in Table 1 . The chemical, physical and mechanical properties adhere to the limit values specified in AS 2350.2, 3, 4, 5, 8 and 11 (SA, 2006).

\section{Chemical properties}

Calcium oxide $(\mathrm{CaO})$

$64 \cdot 5 \%$

Silicon dioxide $\left(\mathrm{SiO}_{2}\right)$

$19 \cdot 3 \%$

Aluminium oxide $\left(\mathrm{Al}_{2} \mathrm{O}_{3}\right)$

$5 \cdot 2 \%$

Iron (III) oxide $\left(\mathrm{Fe}_{2} \mathrm{O}_{3}\right)$

$2 \cdot 9 \%$

Magnesium oxide (MgO)

$1 \cdot 1 \%$

Sulfur trioxide $\left(\mathrm{SO}_{3}\right)$

$2 \cdot 9 \%$

Potassium oxide $\left(\mathrm{K}_{2} \mathrm{O}\right)$

$0.56 \%$

Sodium oxide $\left(\mathrm{Na}_{2} \mathrm{O}\right)$

$<0.01 \%$

Chloride $(\mathrm{Cl})$

$0.02 \%$

Loss on ignition

$2 \cdot 8 \%$

Physical properties

$\begin{array}{lc}\text { Autoclave expansion } & 0.05 \% \\ \text { Fineness index } & 405 \mathrm{~m}^{2} / \mathrm{kg}\end{array}$

Mechanical properties

Initial setting time

90 min

Final setting time $\quad 135 \mathrm{~min}$

Soundness

Drying shrinkage

$1.0 \mathrm{~mm}$

$f_{c}^{\prime}$ (3 days)

$590 \mu$ strain

$f_{c}^{\prime}(7$ days)

$37.2 \mathrm{MPa}$

$f_{c}^{\prime}(28$ days $)$

$47 \cdot 3 \mathrm{MPa}$

$60 \cdot 8 \mathrm{MPa}$

Table 1. Properties of cement

Fly ash

It is important to increase the amount of paste in SCC because it is an agent to carry the aggregates. As a consequence, Eraring fly ash (EFA) has been used to increase the amount of paste. EFA is a natural pozzolan. It is a fine cream/grey powder that is low in lime content. However, in its finely divided form and in the presence of moisture, it will react chemically with calcium hydroxide (e.g., from lime or cement hydration) at ordinary temperatures to form insoluble compounds possessing cementitious properties. The chemical and physical properties of EFA used in the experimental study are given in Table 2 . The chemical, physical and mechanical properties of the EFA used adhere to the limit values specified in AS 2350.2 (SA, 2006), and AS 3583.1, 2, 3, 5, 6, 12 and 13 (SA, 1998).

\section{Ground granulated blast furnace slag}

Granulated blast furnace slag (GGBFS) is another supplementary cementitious material that is used in combination with SLC. GGBFS used in the experiment originated in Boral, Sydney, Australia, and it conformed to AS 3582.2 (SA, 2001) specifications. The chemical and physical properties of GGBFS are given in Table 3.

\section{Aggregate}

In this study, crushed volcanic rock (i.e. latite) coarse aggregate was used with a maximum aggregate size of $10 \mathrm{~mm}$. Nepean 


\section{Chemical properties}

\begin{tabular}{lc}
\hline Aluminium oxide $\left(\mathrm{Al}_{2} \mathrm{O}_{3}\right)$ & $26 \cdot 40 \%$ \\
Calcium oxide $(\mathrm{CaO})$ & $2 \cdot 40 \%$ \\
Iron (III) oxide $\left(\mathrm{Fe}_{2} \mathrm{O}_{3}\right)$ & $3 \cdot 20 \%$ \\
Potassium oxide $\left(\mathrm{K}_{2} \mathrm{O}\right)$ & $1 \cdot 55 \%$ \\
Magnesium oxide $(\mathrm{MgO})$ & $0 \cdot 60 \%$ \\
Manganese $(\mathrm{III})$ oxide $\left(\mathrm{Mn}_{2} \mathrm{O}_{3}\right)$ & $<0 \cdot 1 \%$ \\
Sodium oxide $\left(\mathrm{Na}_{2} \mathrm{O}\right)$ & $0 \cdot 47 \%$ \\
Phosphorous pentoxide $\left(\mathrm{P}_{2} \mathrm{O}_{5}\right)$ & $0 \cdot 20 \%$ \\
Silicon dioxide $\left(\mathrm{SiO}_{2}\right)$ & $61 \cdot 40 \%$ \\
Sulfur trioxide $\left(\mathrm{SO}_{3}\right)$ & $0 \cdot 20 \%$ \\
Strontium oxide $(\mathrm{SrO})$ & $<0 \cdot 1 \%$ \\
Titanium dioxide $\left(\mathrm{TiO}_{2}\right)$ & $1 \cdot 00 \%$ \\
\hline
\end{tabular}

Physical properties

\section{Moisture}

Fineness $45 \mu \mathrm{m}$

Loss on ignition

$$
<0.1 \%
$$

Sulfuric anhydride

$78 \%$ passed

$2.30 \%$

$0 \cdot 20 \%$

$0.50 \%$

Alkali content

Chloride ion

Relative density

$<0.001 \%$

$2.02 \%$

$97 \%$

Relative water requirement

Relative strength 28 days

$88 \%$

Table 2. Properties of fly ash

\begin{tabular}{|c|c|}
\hline Characteristics & Results \\
\hline Sieve size & Passing: $\%$ \\
\hline $13 \cdot 2 \mathrm{~mm}$ & 100 \\
\hline $9.5 \mathrm{~mm}$ & 89 \\
\hline $6.7 \mathrm{~mm}$ & 40 \\
\hline $4.75 \mathrm{~mm}$ & 7 \\
\hline $2 \cdot 36 \mathrm{~mm}$ & 1 \\
\hline $1.18 \mathrm{~mm}$ & 1 \\
\hline Material finer than $75 \mu \mathrm{m}: \%$ & 1 \\
\hline \multicolumn{2}{|l|}{ Mis-shapen particles: \% } \\
\hline Ratio 2:1 & 13 \\
\hline Ratio 3:1 & 1 \\
\hline Flakiness index: \% & 20 \\
\hline Uncompacted bulk density: $\mathrm{t} / \mathrm{m}^{3}$ & $1 \cdot 36$ \\
\hline Compacted bulk density: $t / \mathrm{m}^{3}$ & $1 \cdot 54$ \\
\hline Moisture condition of the aggregate: \% & $1 \cdot 3$ \\
\hline Particle density (Dry): $t / \mathrm{m}^{3}$ & $2 \cdot 65$ \\
\hline Particle density (SSD): $t / \mathrm{m}^{3}$ & $2 \cdot 70$ \\
\hline Apparent particle density: $t / \mathrm{m}^{3}$ & $2 \cdot 79$ \\
\hline Water absorption: \% & 1.9 \\
\hline Ave. dry strength: kN & 391 \\
\hline Ave. wet strength: kN & 293 \\
\hline Wet/dry strength variation: \% & 25 \\
\hline Test fraction: mm & $-9 \cdot 5+6 \cdot 7$ \\
\hline The amount of significant breakdown: \% & $<0 \cdot 2$ \\
\hline \multicolumn{2}{|l|}{ The size of testing cylinder $=150 \mathrm{~mm}$ diam. } \\
\hline Los Angeles Value Grd. 'K': \%Loss & 13 \\
\hline
\end{tabular}

SSD, saturated surface dry.

Table 4. Properties of crushed latite volcanic rock coarse aggregate

\section{Admixtures}

The superplasticiser, viscosity-modifying admixture and highrange water-reducing agent admixture were used in this study. The new superplasticiser generation Glenium 27 complies with AS 1478.1 (SA, 2000a) type high range water reducer and ASTM C494 (ASTM, 2000) types A and F are used. The Rheomac VMA 362 viscosity modifying admixture that was used in this study is a ready-to-use liquid admixture that is specially developed for producing concrete with enhanced viscosity and controlled rheological properties. Pozzolith 80 was used as a highrange water-reducing agent admixture in the mixes. It reduces the quantity of water required to produce concrete of a given consistency, with greater economy, of a given strength. It meets and exceeds AS 1478 (SA, 2000c) Type WRRe, requirements for admixtures.

\section{Fibres}

In this study, two commercially available fibres, Dramix RC-80/ 60-BN type steel fibres and Synmix 65 type polypropylene (PP) fibres were used. The mechanical, elastic and surface structure properties of the steel and PP fibres are summarised in Table 7. 


\begin{tabular}{|c|c|}
\hline Characteristics & Results \\
\hline Sieve size & Passing: \% \\
\hline $6 \cdot 7 \mathrm{~mm}$ & 100 \\
\hline $4.75 \mathrm{~mm}$ & 99 \\
\hline $2 \cdot 36 \mathrm{~mm}$ & 83 \\
\hline $1 \cdot 18 \mathrm{~mm}$ & 64 \\
\hline $600 \mu \mathrm{m}$ & 42 \\
\hline $425 \mu \mathrm{m}$ & 28 \\
\hline $300 \mu \mathrm{m}$ & 19 \\
\hline $150 \mu \mathrm{m}$ & 8 \\
\hline Material finer than $75 \mu \mathrm{m}: \%$ & 3 \\
\hline Uncompacted bulk density: $t / \mathrm{m}^{3}$ & 1.52 \\
\hline Compacted bulk density: $t / \mathrm{m}^{3}$ & 1.64 \\
\hline Particle density (dry): t/m $\mathrm{m}^{3}$ & $2 \cdot 58$ \\
\hline Particle density (SSD): t/m³ & $2 \cdot 60$ \\
\hline Apparent particle density: $t / \mathrm{m}^{3}$ & $2 \cdot 63$ \\
\hline Water absorption: \% & $0 \cdot 7$ \\
\hline Silt content: \% & 7 \\
\hline Degradation factor of fine aggregate & 90 \\
\hline \multicolumn{2}{|l|}{$\begin{array}{l}\text { The wash water after using permitted } 500 \mathrm{ml} \\
\text { was: CLEAR }\end{array}$} \\
\hline Moisture content: \% & $5 \cdot 5$ \\
\hline \multicolumn{2}{|l|}{ Method of determining voids content } \\
\hline$\%$ voids & $41 \cdot 7$ \\
\hline The mean flow time: $\mathrm{s}$ & $26 \cdot 5$ \\
\hline
\end{tabular}

SSD, saturated surface dry.

Table 5. Properties of Nepean river gravel fine aggregate

\section{Mixture proportions}

One control SCC mixture (N-SCC) and three FRSCC mixtures were used in this study. FRSCC mixtures contained steel (D-SCC), PP (S-SCC) and hybrid (steel + PP) (DS-SCC) fibres. The content proportions of these mixtures are given in Table 8 . These contents were chosen to attempt to keep compressive strength to a level applicable to construction.

\section{Samples' preparation and curing conditions}

We used $\phi 150 \mathrm{~mm} \times 300 \mathrm{~mm}$ molds for the determination of compressive and splitting tensile strengths, and cylindrical molds $\phi 150 \mathrm{~mm} \times 300 \mathrm{~mm}$ were used for the determination of the modulus of elasticity. Meanwhile, $100 \mathrm{~mm} \times 100 \mathrm{~mm} \times 350 \mathrm{~mm}$ molds were used for the determination of modulus of rupture.

\begin{tabular}{lc}
\hline Characteristics & Results \\
\hline Sieve size & Passing: \% \\
$1.18 \mathrm{~mm}$ & 100 \\
$600 \mu \mathrm{m}$ & 98 \\
$425 \mu \mathrm{m}$ & 87 \\
$300 \mu \mathrm{m}$ & 46 \\
$150 \mu \mathrm{m}$ & 1 \\
Material finer than $75 \mu \mathrm{m}$ in aggregate by & $\mathrm{Nil}$ \\
washing: \% & \\
Uncompacted bulk density: $\mathrm{t} / \mathrm{m}^{3}$ & 1.39 \\
Compacted bulk density: $\mathrm{t} / \mathrm{m}^{3}$ & 1.54 \\
Particle density (dry): $\mathrm{t} / \mathrm{m}^{3}$ & $2 \cdot 58$ \\
Particle density (SSD): $\mathrm{t} / \mathrm{m}^{3}$ & 2.59 \\
Apparent particle density: $\mathrm{t} / \mathrm{m}^{3}$ & 2.62 \\
Water absorption: \% & 0.6 \\
Silt content: \% & 4
\end{tabular}

SSD, saturated surface dry.

Table 6. Properties of Kurnell natural river sand fine aggregate

Specimens for testing the hardened properties were prepared by direct pouring of concrete into molds without compaction. The specimens were kept covered in a controlled chamber at $20 \pm 2^{\circ} \mathrm{C}$ for $24 \mathrm{~h}$ until demolding. Thereafter, the specimens were placed in water presaturated with lime at $20^{\circ} \mathrm{C}$. These specimens were tested at $3,7,14,28,56$ and 91 days.

\section{Samples" test methods}

The compressive strength test, performed on $\phi 150 \mathrm{~mm} \times$ $300 \mathrm{~mm}$ cylinders, followed AS 1012.14 (SA, 1991) and ASTM C39 (ASTM, 2000) tests for compressive strength of cylindrical concrete specimens. The cylinders were loaded in a testing machine under load control at the rate of $0.3 \mathrm{MPa} / \mathrm{s}$ until failure. The splitting tensile test, run on $\phi 150 \mathrm{~m} \mathrm{~m} \times 300 \mathrm{~mm}$ cylinders, was in accordance with the AS 1012.10 (SA, 2000a) and ASTM C496 (ASTM, 2000) tests for splitting tensile strength of cylindrical concrete specimens, although ACI committee 544.2R (ACI, 1999) hardly recommends the use of the test on FRC. The running arose because the ratio of fibre length to cylinder diameter took a low value of 0.23 in the work and because some investigators have shown that the ASTM C496 test is applicable to FRC specimens.

\begin{tabular}{|c|c|c|c|c|c|c|c|c|c|}
\hline Fibre type & Fibre name & $\begin{array}{c}\text { Density: } \\
\mathrm{kg} / \mathrm{m}^{3}\end{array}$ & $\begin{array}{l}\text { Length } \\
(/)\end{array}$ & $\begin{array}{c}\text { Diameter } \\
(d)\end{array}$ & $\begin{array}{c}\text { Aspect } \\
\text { ratio } \\
(I / d)\end{array}$ & $\begin{array}{c}\text { Tensile } \\
\text { strength: } \\
\text { MPa }\end{array}$ & $\begin{array}{c}\text { Modulus of } \\
\text { elasticity: } \\
\text { GPa }\end{array}$ & $\begin{array}{l}\text { Cross- } \\
\text { section } \\
\text { form }\end{array}$ & $\begin{array}{l}\text { Surface } \\
\text { structure }\end{array}$ \\
\hline Steel & Dramix RC-80/60-BN & 7850 & 60 & 0.75 & $80 \cdot 0$ & 1050 & 200 & Circular & Hooked end \\
\hline Polypropylene & Synmix 65 & 905 & 65 & 0.85 & $76 \cdot 5$ & 250 & 3 & Square & Rough \\
\hline
\end{tabular}

Table 7. The physical and mechanical properties of fibres 


\begin{tabular}{lcccc}
\hline Constituents & N-SCC & D-SCC & S-SCC & DS-SCC \\
\hline Cement: kg/m & 160 & 160 & 160 & 160 \\
Fly ash: $\mathrm{kg} / \mathrm{m}^{3}$ & 130 & 130 & 130 & 130 \\
GGBFS: $\mathrm{kg} / \mathrm{m}^{3}$ & 110 & 110 & 110 & 110 \\
Cementitious content: kg/m $\mathrm{m}^{3}$ & 400 & 400 & 400 & 400 \\
Water: lit/m & 208 & 208 & 208 & 208 \\
Water cementitious ratio & 0.52 & 0.52 & 0.52 & 0.52 \\
\hline
\end{tabular}

Fine aggregate: $\mathrm{kg} / \mathrm{m}^{3}$

\begin{tabular}{lllll}
\hline Coarse sand & 660 & 660 & 660 & 660 \\
Fine sand & 221 & 221 & 221 & 221 \\
Coarse aggregate: $\mathrm{kg} / \mathrm{m}^{3}$ & 820 & 820 & 820 & 820 \\
\hline
\end{tabular}

Admixtures: $1 \mathrm{it} / \mathrm{m}^{3}$

\begin{tabular}{lllll}
\hline Superplasticiser & 4 & 4.86 & 4.73 & 4.5 \\
VMA & 1.3 & 1.3 & 1.3 & 1.3 \\
High range water reducing agent & 1.6 & 1.6 & 1.6 & 1.6 \\
\hline
\end{tabular}

Fibre content: $\mathrm{kg} / \mathrm{m}^{3}$

\begin{tabular}{llccc}
\hline Steel & - & 30 & - & 15 \\
PP & - & - & 5 & 3 \\
\hline
\end{tabular}

N-SCC, control self-compacting concrete (SCC) mixture; D-SCC, fibre-reinforced SCC (FRSCC) with steel fibres; S-SCC, FRSCC containing polypropylene (PP) fibres; DS-SCC, FRSCC containing hybrid steel and PP fibres; GGBFS, granulated blast furnace slag; VMA, viscosity-modifying admixtures.

Table 8. The proportions of the concrete mixtures (based on saturated surface dry condition)

The modulus of elasticity test that followed the AS 1012.17 (SA, 1997) and ASTM C469 was done to $\phi 150 \mathrm{~mm} \times 300 \mathrm{~mm}$ cylinders. The flexural strength (modulus of rupture) test, conducted using $100 \mathrm{~mm} \times 100 \mathrm{~mm} \times 350 \mathrm{~mm}$ test beams under third-point loading, followed the AS 1012.11 (SA, 2000b) and ASTM C1018 test for flexural toughness and first-crack strength of fibre-reinforced concrete. The mid-span deflection was the average of the ones detected by the transducers through contact with brackets attached to the beam specimen.

\section{Properties of fresh concrete}

The experiments required for the SCC are generally carried out worldwide under laboratory conditions. These experiments test the liquidity, segregation, placement and compacting of fresh concrete. Conventional workability experiments are not sufficient for the evaluation of SCC. Some of the experimental methods developed to measure the liquidity, segregation, placement and compaction of SCC are defined in the European guidelines (EFNARC, 2005) and ACI 237R-07 (ACI, 2007) for SCC, including specification, production and use as slump-flow, V-funnel, U-box, L-box and fill-box tests.
This study performed slump flow, $T_{50 \mathrm{~cm}}$ time, J-ring flow, V-funnel flow time and L-box blocking ratio tests. In order to reduce the effect of loss of workability on the variability of test results, the fresh properties of the mixes were determined within $30 \mathrm{~min}$ after mixing. The order of testing is as follows: $(a)$ slump flow test and measurement of $T_{50 \mathrm{~cm}}$ time; (b) J-ring flow test, measurement of difference in height of concrete inside and outside the J-ring, and measurement of $T_{50 \mathrm{~cm}}$ time; (c) V-funnel flow tests at $10 \mathrm{~s} T_{10 \mathrm{~s}}$ and $5 \mathrm{~min} T_{5 \mathrm{~min}}$; and (d) L-box test.

\section{Experimental results}

Properties of fresh concrete

The results of various fresh properties tested by the slump flow test (slump flow diameter and $T_{50 \mathrm{~cm}}$ ); J-ring test (flow diameter); L-box test (time taken to reach $400 \mathrm{~mm}$ distance $T_{400 \mathrm{~mm}}$, time taken to reach $600 \mathrm{~mm}$ distance $T_{600 \mathrm{~mm}}$, time taken to reach $800 \mathrm{~mm}$ distance $T_{\mathrm{L}}$ and ratio of heights at the two edges of L-box $\left[\mathrm{H}_{2} / \mathrm{H}_{1}\right]$ ); and the V-funnel test (time taken by concrete to flow through $\mathrm{V}$-funnel after $10 \mathrm{~s} T_{10 \mathrm{~s}}$, and time taken by concrete to flow through V-funnel after 5 min $T_{5 \mathrm{~min}}$ ); the amount of 


\begin{tabular}{|c|c|c|c|c|}
\hline Workability characteristics & $\mathrm{N}-\mathrm{SCC}$ & D-SCC & S-SCC & DS-SCC \\
\hline Average spreading diameter: $\mathrm{mm}$ & 680 & 670 & 700 & 650 \\
\hline Flow time $T_{50 \mathrm{~cm}}: \mathrm{s}$ & $2 \cdot 7$ & $3 \cdot 8$ & $2 \cdot 5$ & $3 \cdot 2$ \\
\hline Average J-ring diameter: $\mathrm{mm}$ & 655 & 580 & 570 & 560 \\
\hline Flow time $T_{50 \mathrm{~cm}} \mathrm{~J}$-ring: $\mathrm{s}$ & $3 \cdot 2$ & 5 & 6 & 5 \\
\hline L-box test & $0 \cdot 87$ & Blocked & Blocked & Blocked \\
\hline Flow time $V$-funnel: s & 6 & 7 & Blocked & Blocked \\
\hline$V$-funnel at $T_{5 \text { minutes }}: \mathrm{s}$ & 4 & 5 & Blocked & Blocked \\
\hline Entrapped air: \% & $1 \cdot 3$ & $1 \cdot 2$ & $1 \cdot 2$ & 1.0 \\
\hline Specific gravity: kg/m³ & 2340 & 2274 & 2330 & 2385 \\
\hline
\end{tabular}

N-SCC, control SCC mixture; D-SCC, fibre-reinforced SCC (FRSCC) with steel fibres; S-SCC, FRSCC with polypropylene (PP) fibres; DS-SCC, FRSCC with hybrid steel and PP fibres.

Table 9. The self-compacting concrete (SCC) mixes workability characteristics

entrapped air; and the specific gravity of mixes are given in Table 9. The slump flow test judges the capability of concrete to deform under its own weight against the friction of the surface with no restraint present. A slump flow value ranging from 500 to $700 \mathrm{~mm}$ for SCC was suggested (EFNARC, 2005). At a slump flow $>700 \mathrm{~mm}$, the concrete might segregate and, at $<500 \mathrm{~mm}$, the concrete might have insufficient flow to pass through highly congested reinforcements. All the mixes in the present study conform to the above range because the slump flow of SCC is in the range of $600-700 \mathrm{~mm}$. The slump flow time for the concrete to reach a diameter of $500 \mathrm{~mm}$ for all mixes was less than $4.5 \mathrm{~s}$. The J-ring diameters were in the range of $560-655 \mathrm{~mm}$. In addition to the slump flow test, a V-funnel test was also performed to assess the flowability and stability of SCC. V-funnel flow time is the elapsed time in seconds between the opening of the bottom outlet, depending on when it is opened $\left(T_{10 \mathrm{~s}}\right.$ and $\left.T_{5 \mathrm{~min}}\right)$, and the time when light becomes visible at the bottom when observed from the top. A V-funnel time of less than $6 \mathrm{~s}$ is recommended for SCC. According to EFNARC (2005), a period ranging from 6 to $12 \mathrm{~s}$ is considered adequate for SCC. The V-funnel flow times in the experiment were in the range of $4-10 \mathrm{~s}$. The test results of this investigation indicated that all N-SCC and D-SCC mixes met the requirements of allowable flow time, but the S-SCC and DS-SCC mixes were blocked. The maximum size of coarse aggregates was restricted to $10 \mathrm{~mm}$ to avoid a blocking effect in the L-box. The gap between rebars in the L-box test was $35 \mathrm{~mm}$. The L-box ratio $\mathrm{H}_{2} / \mathrm{H}_{1}$ for the N-SCC mix was above 0.8 which is, according to EFNARC standards and, obviously, for other mixes, blocked.

\section{Compressive strength}

Figure 1 presents the compressive strength of N-SCC, D-SCC, S-SCC and DS-SCC mixes achieved at different ages. Compressive strength samples with fibre mixes are higher than the N-SCC mix. Samples with the S-SCC mix have lower compressive strength, unlike the D-SCC and DS-SCC mixes. The average compressive strength of the DS-SCC mix is $18 \cdot 90 \%, 3 \cdot 83 \%$ and

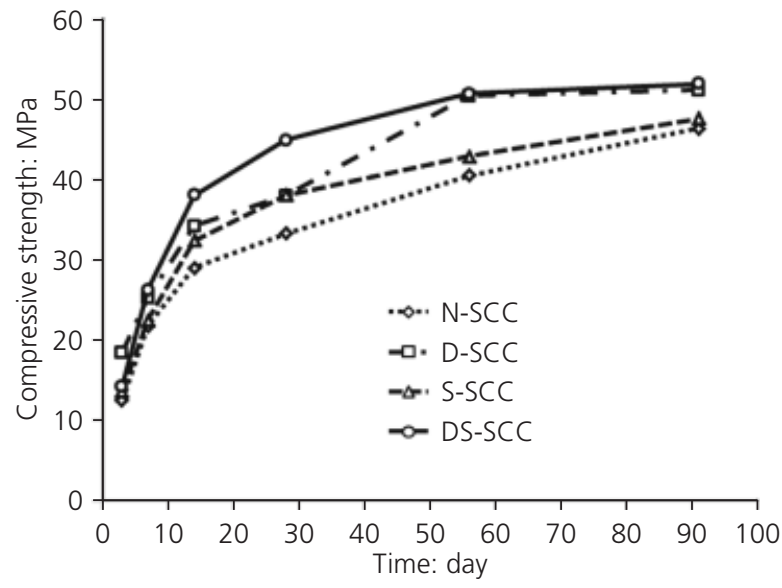

Figure 1. Compressive strength of self-compacting concrete (SCC) mixtures at different ages. N-SCC, control SCC mixture; D-SCC, fibre-reinforced SCC (FRSCC) with steel fibres; S-SCC, FRSCC with polypropylene (PP) fibres; DS-SCC, FRSCC with hybrid steel and PP fibres

$12 \cdot 86 \%$ higher than the N-SCC, D-SCC and S-SCC mixes respectively. The results show that the D-SCC mix at three days was $32 \cdot 57 \%, 26 \cdot 13 \%$ and $22 \cdot 73 \%$ higher than the N-SCC, S-SCC and DS-SCC mixes respectively. Furthermore, the results indicate that the compressive strength of the DS-SCC mix at 91 days is $10.71 \%, 1.62 \%$ and $8.32 \%$ higher than the N-SCC, DSCC and S-SCC mixes respectively.

\section{Tensile strength}

Figure 2 shows the splitting tensile strengths of the N-SCC, D-SCC, S-SCC and DS-SCC mixes determined at different ages. The tensile strengths of the D-SCC and DS-SCC samples are higher than those of the N-SCC and S-SCC. The S-SCC mix has a lower tensile strength than $\mathrm{N}-\mathrm{SCC}$. The average tensile strength 


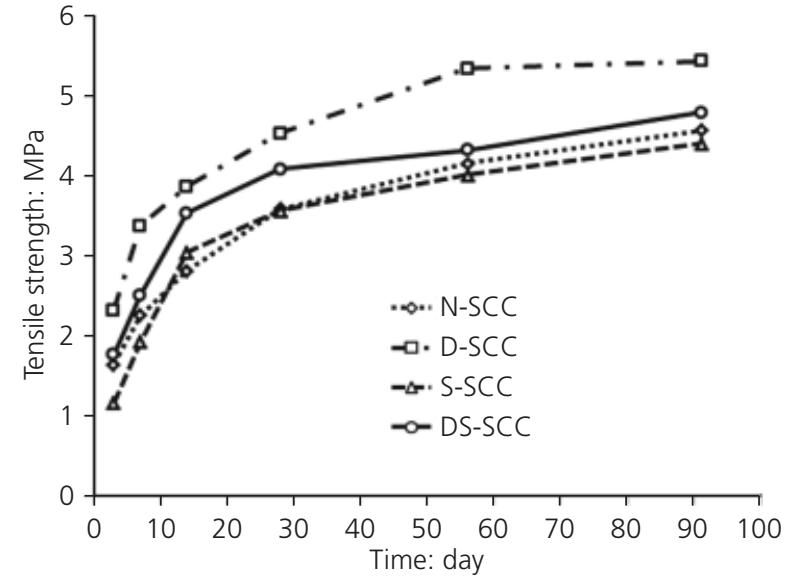

Figure 2. Tensile strength of self-compacting concrete (SCC) mixtures at different ages. N-SCC, control SCC mixture; D-SCC, fibre-reinforced SCC (FRSCC) with steel fibres; S-SCC, FRSCC with polypropylene (PP) fibres; DS-SCC, FRSCC with hybrid steel and PP fibres

of the D-SCC mix is $23 \cdot 52 \%, 27 \cdot 19 \%$ and $15 \cdot 54 \%$ higher than that of the N-SCC, S-SCC and DS-SCC mixes respectively. Moreover, the results indicate that the tensile strength of the D-SCC mix at 91 days is $15.95 \%, 18.89 \%$ and $11.76 \%$ higher than that of the N-SCC, S-SCC and DS-SCC mixes respectively.

\section{Modulus of elasticity}

Figure 3 presents the modulus of elasticity of the N-SCC, D-SCC, S-SCC and DS-SCC mixes attained at different ages. The average modulus of elasticity of the DS-SCC mix is $2.67 \%$, $4.75 \%$ and $3.49 \%$ higher than that of the N-SCC, D-SCC and S-SCC mixes respectively. The results show that the N-SCC mix at 14 days is $9 \cdot 62 \%, 7 \cdot 94 \%$ and $3.03 \%$ higher than the D-SCC,

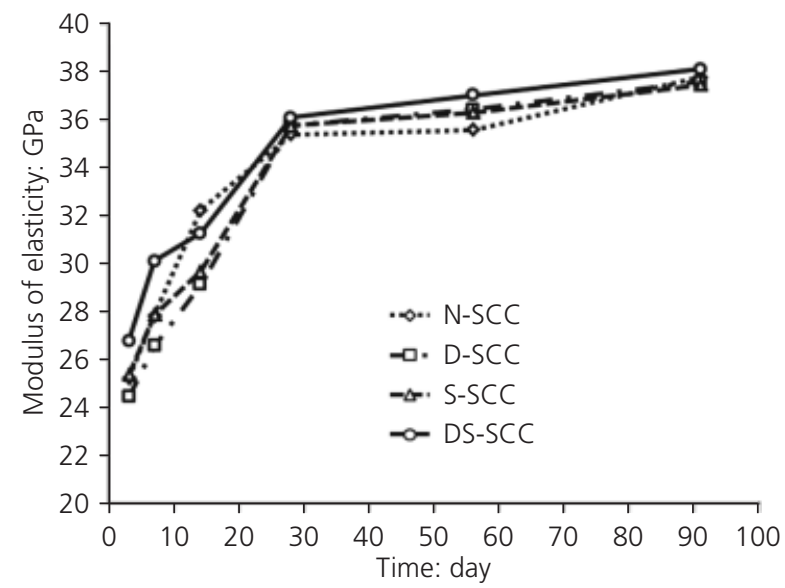

Figure 3. Modulus of elasticity of self-compacting concrete (SCC) mixtures at different ages. N-SCC, control SCC mixture; D-SCC, fibre-reinforced SCC (FRSCC) with steel fibres; S-SCC, FRSCC with polypropylene (PP) fibres; DS-SCC, FRSCC with hybrid steel and PP fibres
S-SCC and DS-SCC mixes respectively. Additionally, the results indicate that the tensile strength of the DS-SCC mix at 91 days is $0.86 \%, 1.41 \%$ and $1.72 \%$ higher than that of the N-SCC, D-SCC and S-SCC mixes respectively.

\section{Modulus of rupture (flexural tensile strength)}

Figure 4 illustrates the flexural tensile strengths of the N-SCC, D-SCC, S-SCC and DS-SCC mixes determined at different ages. The average flexural tensile strength of the D-SCC mix is $13.96 \%, 8.80 \%$ and $8.89 \%$ higher than that of the N-SCC, S-SCC and DS-SCC mixes respectively. The results show that the S-SCC mix at 7 days is $21.30 \%, 3.97 \%$ and $10.52 \%$ higher than the N-SCC, D-SCC and DS-SCC mixes respectively. Also, the results indicate that flexural tensile strength of the D-SCC mix at 91 days is $1 \cdot 30 \%, 6 \cdot 44 \%$ and $0 \cdot 21 \%$ higher than that of the N-SCC, S-SCC and DS-SCC mixes respectively.

\section{Compressive stress-strain curve}

Complete stress-strain curves of the concrete specimens were obtained from the compression tests of the cylinders with a controlled displacement rate. For each mix, three cylinders were tested. As the test results reproduced well, each stress-strain curve shown in Figures 5-8 represents the average results of the three tests. It should be noted that the axial strains of the concrete in compression were obtained from the full height shortening of the cylinders using linear variable differential transformers. The compression stress-strain curves at increasing ages of the N-SCC, D-SCC, S-SCC and DS-SCC mixes are shown in Figures 5-8. All the fibrous SCC mixes verified more substantial ductility than the corresponding N-SCC mix. Commonly, the nature of failure in compression for the N-SCC mix tended to be more sudden and brittle as the age of the concrete increased. However, with the increasing age, the majority of the

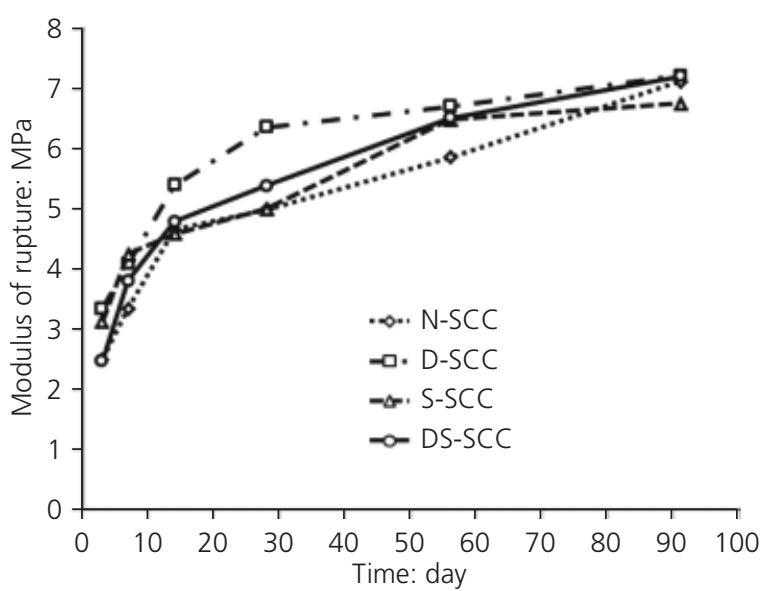

Figure 4. Modulus of rupture of self-compacting concrete (SCC) mixtures at different ages. N-SCC, control SCC mixture; D-SCC, fibre-reinforced SCC (FRSCC) with steel fibres; S-SCC, FRSCC with polypropylene (PP) fibres; DS-SCC, FRSCC with hybrid steel and PP fibres 
Mechanical characteristics of selfcompacting concrete with and without fibres

Aslani and Nejadi

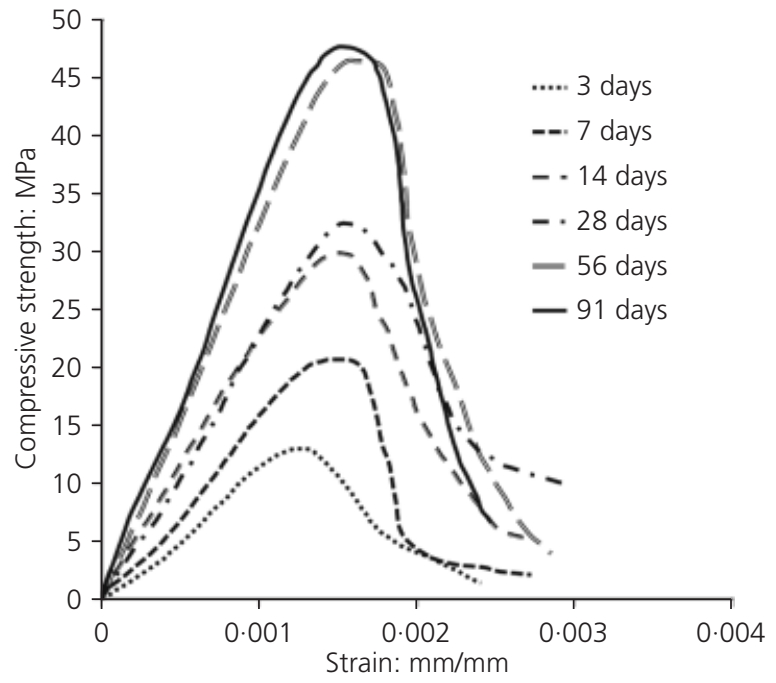

Figure 5. Compressive stress-strain curve of the control selfcompacting concrete mixture mix at different ages

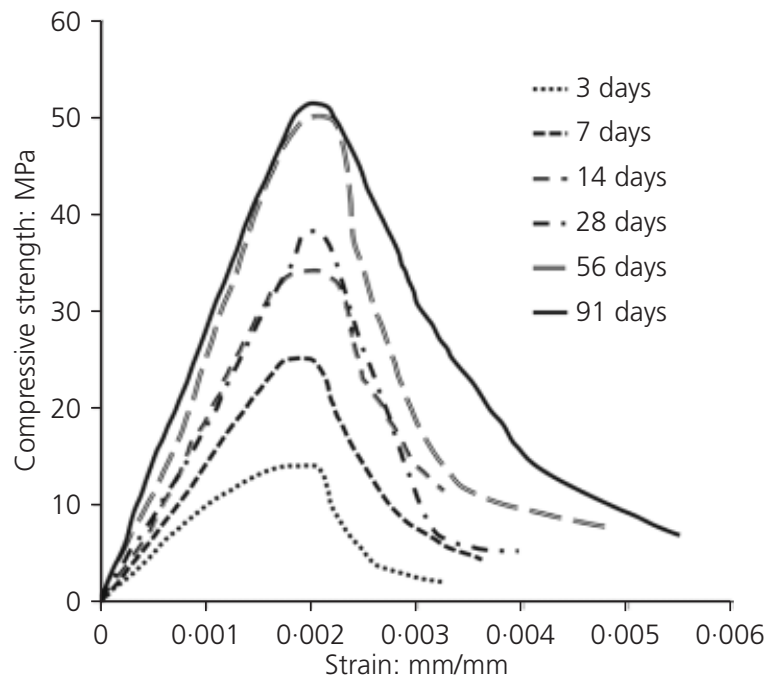

Figure 6. Compressive stress-strain curve of the fibre-reinforced self-compacting concrete containing steel fibres mix at different ages

fibrous SCC mixes maintained their ductility and gradual failure mechanism.

\section{Analytical relationships for the mechanical properties}

Time-related mechanical properties relationships

To estimate the SCC mixes' compressive strength, tensile strength, modulus of elasticity and modulus of rupture at various ages, Equations 1-4 are proposed based on regression analyses of the experimental data. Figure 9 shows that the proposed time-

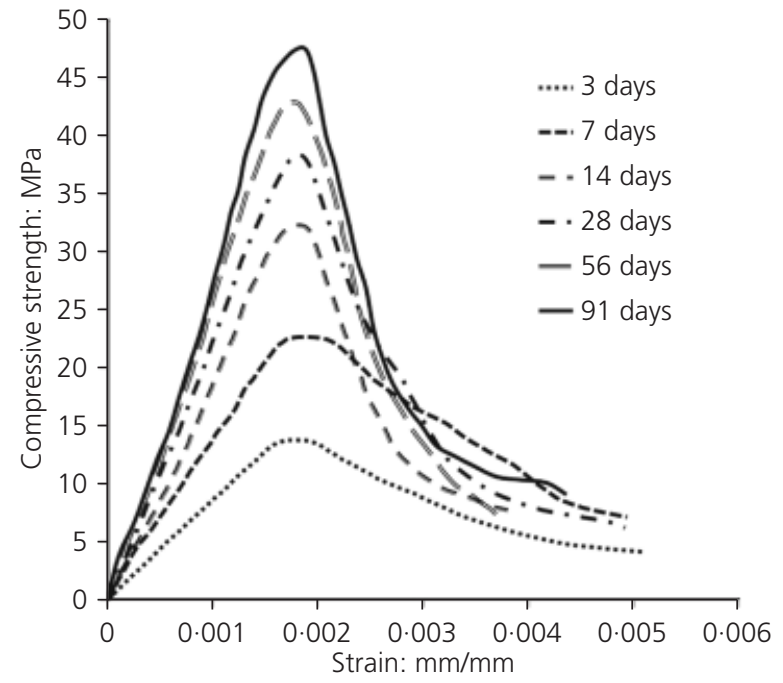

Figure 7. Compressive stress-strain curve of the fibre-reinforced self-compacting concrete containing polypropylene fibres mix at different ages

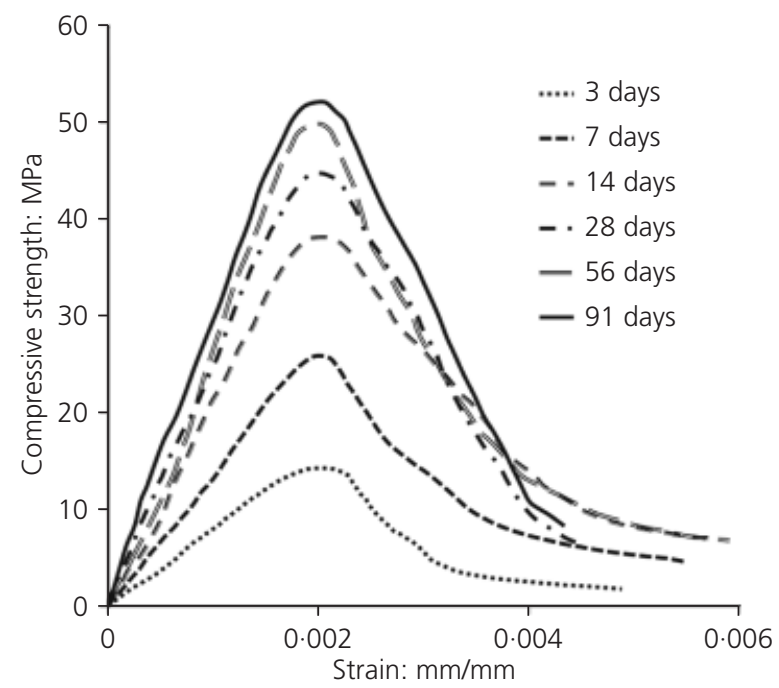

Figure 8. Compressive stress-strain curve of the fibre-reinforced self-compacting concrete containing hybrid steel and polypropylene fibres mix at different ages

related relationships of compressive strength, tensile strength, modulus of elasticity and modulus of rupture are in good agreement with the experimental results.

Compressive strength

1. $f_{\mathrm{cm}}(t)=\frac{f_{\mathrm{c}}^{\prime}}{\alpha} \ln (t)+\beta$

where $f_{\mathrm{cN}}^{\prime}$ is the N-SCC mix compressive strength, $f_{\mathrm{cfD}}^{\prime}$ is the 
Mechanical characteristics of selfcompacting concrete with and without

fibres

Aslani and Nejadi

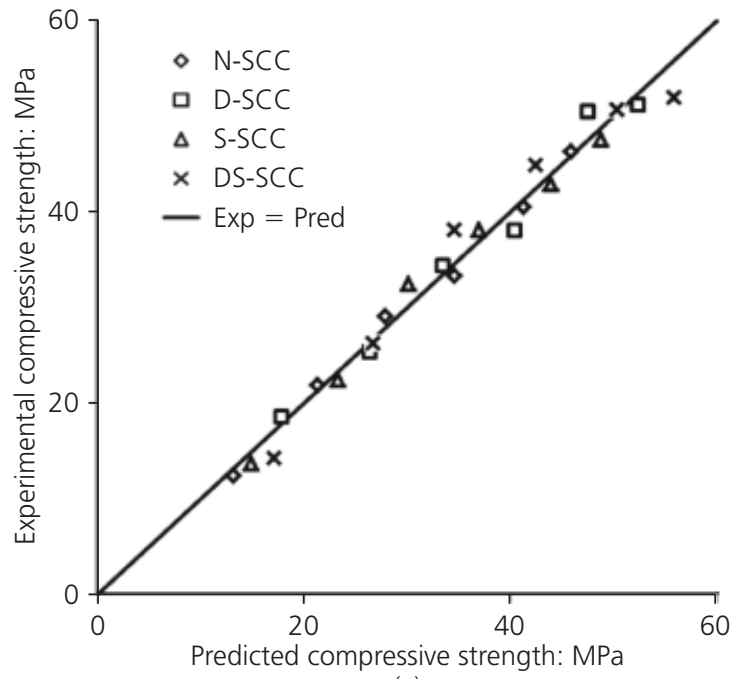

(a)

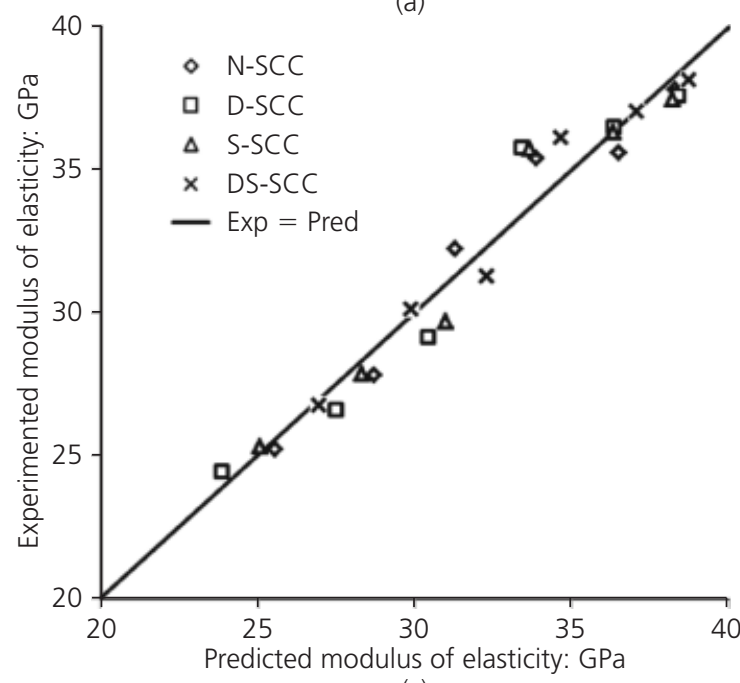

(c)

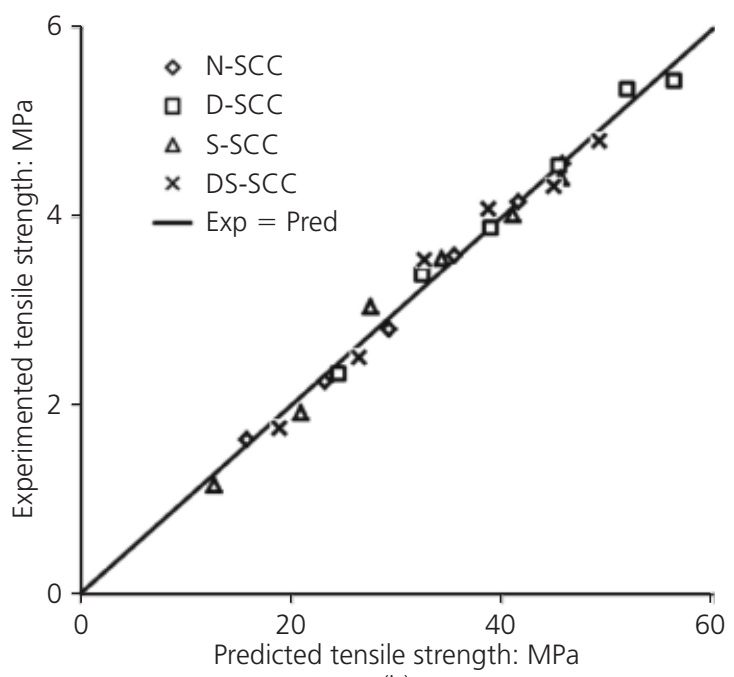

(b)

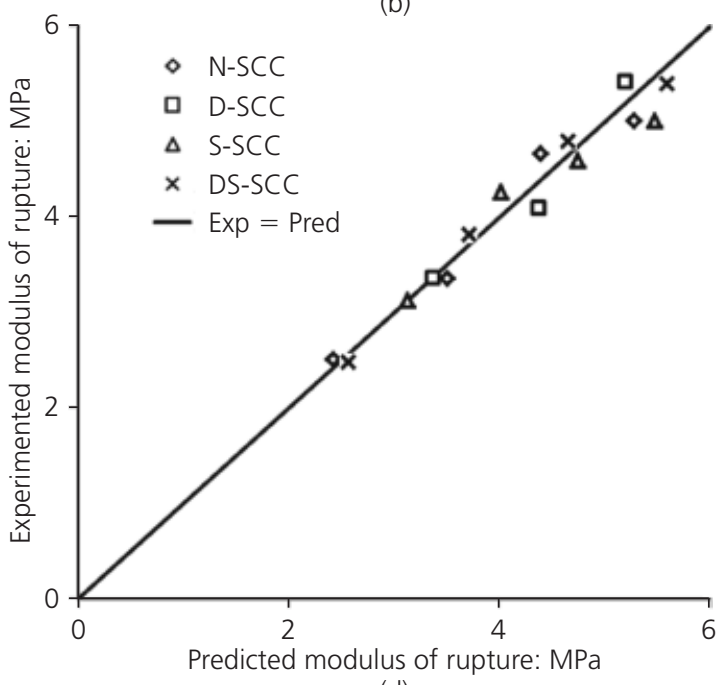

(d)

Figure 9. Predicted time-related mechanical properties values versus experimented values (a) compressive strength, (b) tensile strength, (c) modulus of elasticity and (d) modulus of rupture. N-SCC, control SCC mixture; D-SCC, fibre-reinforced SCC (FRSCC) with steel fibres; S-SCC, FRSCC with polypropylene (PP) fibres; DS-SCC, FRSCC with hybrid steel and PP fibres

D-SCC mix compressive strength, $f_{\mathrm{cfS}}^{\prime}$ is the S-SCC mix compressive strength, $f_{\text {cfDS }}^{\prime}$ is the DS-SCC mix compressive strength, and $\alpha$ and $\beta$ are the empirical constants (Table 10).

Tensile strength

2. $f_{\mathrm{ctm}}(t)=\frac{f_{\mathrm{ct}}}{\gamma} \ln (t)+\lambda$

where $f_{\mathrm{ctN}}^{\prime}$ is the N-SCC mix tensile strength, $f_{\mathrm{ctfD}}^{\prime}$ is the D-SCC mix tensile strength, $f_{\text {ctfS }}^{\prime}$ is the S-SCC mix tensile strength,

\begin{tabular}{llcc}
\hline Mix & $f_{c}^{\prime}$ & $\alpha$ & $\beta$ \\
\hline N-SCC & $f_{\text {cN }}^{\prime}$ & 3.47 & 2.54 \\
D-SCC & $f_{\text {cfD }}^{\prime}$ & 3.75 & 6.66 \\
S-SCC & $f_{\text {cfS }}^{\prime}$ & 3.84 & 3.87 \\
DS-SCC & $f_{\text {CfDS }}^{\prime}$ & 3.96 & 4.54 \\
\hline
\end{tabular}

N-SCC, control SCC mixture; D-SCC, fibre-reinforced SCC (FRSCC) with steel fibres; S-SCC, FRSCC with polypropylene (PP) fibres; DS-SCC, FRSCC with hybrid steel and PP fibres.

Table 10. Equation 1 constant components for different mixes 
$f_{\text {ctfDS }}^{\prime}$ is the DS-SCC mix tensile strength, and $\gamma$ and $\lambda$ are the empirical constants. (Table 11)

\section{Modulus of elasticity}

$$
\text { 3. } E_{\mathrm{cm}}(t)=\frac{E_{\mathrm{c}}}{\eta} \ln (t)+\mu
$$

where $E_{\mathrm{cN}}$ is the N-SCC mix modulus of elasticity, $E_{\mathrm{cfD}}$ is the D-SCC mix modulus of elasticity, $E_{\mathrm{cfS}}$ is the S-SCC mix modulus of elasticity, $E_{\mathrm{cfDS}}$ is the DS-SCC mix modulus of elasticity, and $\eta$ and $\mu$ are the empirical constants (Table 12).

\section{Modulus of rupture}

4. $f_{\mathrm{crm}}(t)=\frac{f_{\mathrm{cr}}}{\psi} \ln (t)+\phi$

where $f_{\text {crN }}$ is the N-SCC mix modulus of rupture, $f_{\text {crfD }}$ is the D-SCC mix modulus of rupture, $f_{\text {crfs }}$ is the S-SCC mix modulus of rupture, $f_{\text {crfDs }}$ is the DS-SCC mix modulus of rupture, and $\psi$ and $\phi$ are the empirical constants (Table 13).

\begin{tabular}{llcl}
\hline Mix & $f_{\mathrm{ct}}$ & $\gamma$ & $\lambda$ \\
\hline N-SCC & $f_{\text {ctN }}^{\prime}$ & 4.09 & 0.60 \\
D-SCC & $f_{\text {ctfD }}^{\prime}$ & 4.87 & 1.43 \\
S-SCC & $f_{\text {ctfS }}^{\prime}$ & 3.69 & 0.19 \\
DS-SCC & $f_{\text {ctfDS }}^{\prime}$ & 4.60 & 0.91 \\
\hline
\end{tabular}

N-SCC, control SCC mixture; D-SCC, fibre-reinforced SCC (FRSCC) with steel fibres; S-SCC, FRSCC with polypropylene (PP) fibres; DS-SCC, FRSCC with hybrid steel and PP fibres.

Table 11. Equation 2 constant components for different mixes

\begin{tabular}{llrc}
\hline Mix & $E_{\mathrm{C}}$ & $\eta$ & $\mu$ \\
\hline N-SCC & $E_{\mathrm{CN}}$ & $9 \cdot 47$ & 21.42 \\
D-SCC & $E_{\mathrm{CfD}}$ & $8 \cdot 40$ & $19 \cdot 20$ \\
S-SCC & $E_{\mathrm{CfS}}$ & $9 \cdot 30$ & 20.83 \\
DS-SCC & $E_{\mathrm{CfDS}}$ & 10.47 & 23.15 \\
\hline
\end{tabular}

N-SCC, control SCC mixture; D-SCC, fibre-reinforced SCC (FRSCC) with steel fibres; S-SCC, FRSCC with polypropylene (PP) fibres; DS-SCC, FRSCC with hybrid steel and PP fibres.

Table 12. Equation 3 constant components for different mixes

\begin{tabular}{llcc}
\hline Mix & $f_{\text {cr }}$ & $\psi$ & $\phi$ \\
\hline N-SCC & $f_{\text {crN }}$ & 3.89 & 1.00 \\
D-SCC & $f_{\text {crfD }}$ & 5.39 & 2.07 \\
S-SCC & $f_{\text {crfs }}$ & 4.75 & 1.96 \\
DS-SCC & $f_{\text {crfDS }}$ & 3.99 & 1.08 \\
\hline
\end{tabular}

N-SCC, control SCC mixture; D-SCC, fibre-reinforced SCC (FRSCC) with steel fibres; S-SCC, FRSCC with polypropylene (PP) fibres; DS-SCC, FRSCC with hybrid steel and PP fibres.

Table 13. Equation 4 constant components for different mixes

\section{Compressive strength-related mechanical properties relationships}

Figure 10 illustrates tensile strength, modulus of elasticity and modulus of rupture versus compressive strength. Equations 5-7 are proposed based on regression analyses of the experimental data to predict the SCC mixes' tensile strength, modulus of elasticity and modulus of rupture based on the compressive strength. The bases of the proposed relationships are captured from Aslani and Nejadi's (2012a) study. Figure 11 indicates that the proposed compressive strength-related relationships of tensile strength, modulus of elasticity and modulus of rupture are in good agreement with the experimental results.

\section{Tensile strength}

5. $f_{\mathrm{ct}}=\eta_{1}\left(f_{\mathrm{c}}^{\prime}\right)^{\eta_{2}}$

(Table 14)

Modulus of elasticity

6. $E_{\mathrm{c}}=\kappa_{1}\left(f_{\mathrm{c}}^{\prime}\right)^{\kappa_{2}}$

(Table 15)

\section{Modulus of rupture}

7. $f_{\mathrm{cr}}=\delta_{1}\left(f_{\mathrm{c}}^{\prime}\right)^{\delta_{2}}$

(Table 16)

\section{Compressive stress-strain relationship}

In this study, a compressive stress-strain relationship (Equations 8-15) for SCC mixes that is based on Aslani and Nejadi's (2012a) model was developed by using the proposed compressive strength (Equation 1) and elastic modulus (Equations 3 and 6) relationships. Figure 12 shows that the proposed stress-strain relationship fits the experimental results well. In Figure 12, 
Mechanical characteristics of self-

compacting concrete with and without

fibres

Aslani and Nejadi

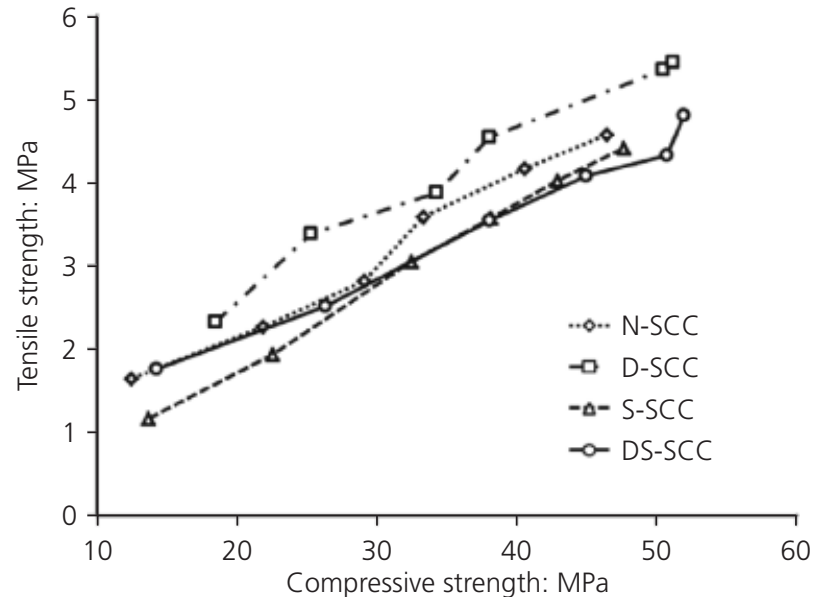

(a)

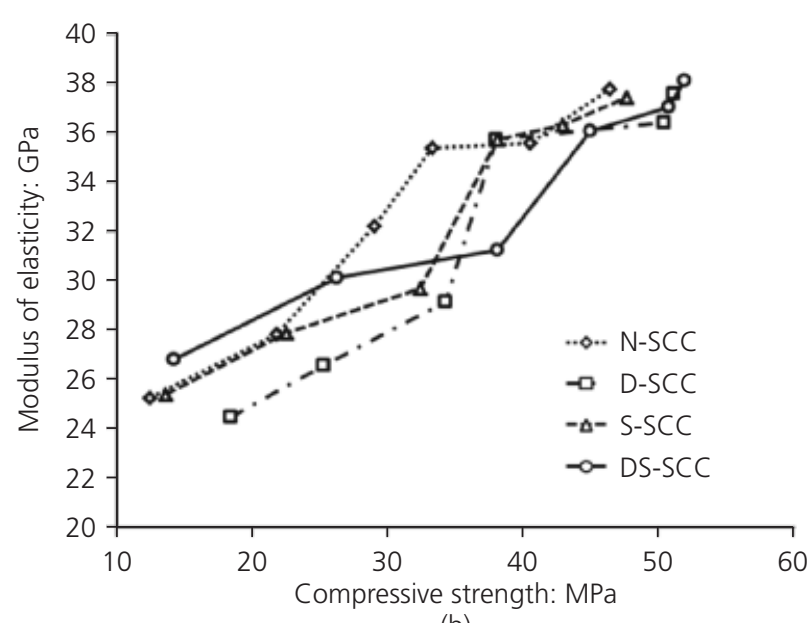

(b)

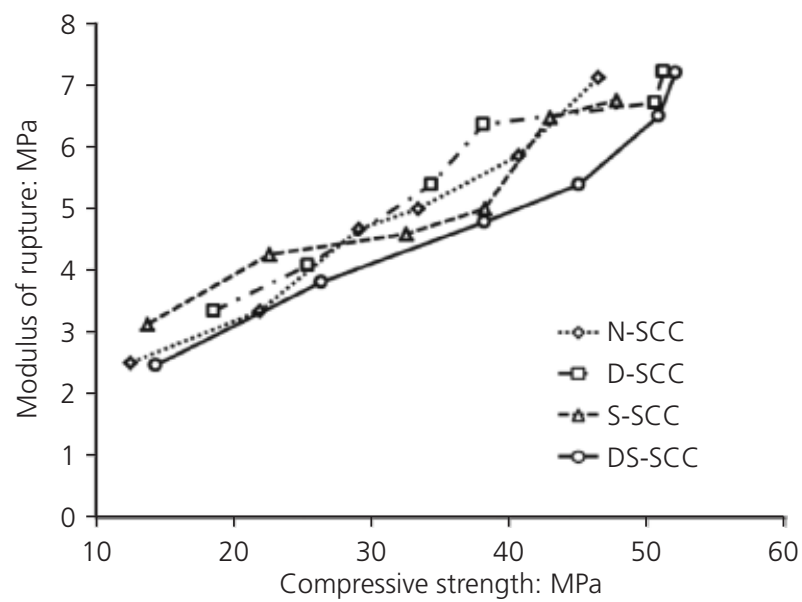

(c)

Figure 10. Experimented compressive strength-related mechanical properties (a) tensile strength, (b) modulus of elasticity and (c) modulus of rupture. N-SCC, control SCC mixture; D-SCC, fibre-reinforced SCC (FRSCC) with steel fibres; S-SCC, FRSCC with poly-propylene (PP) fibres; DS-SCC, FRSCC with hybrid steel and PP fibres

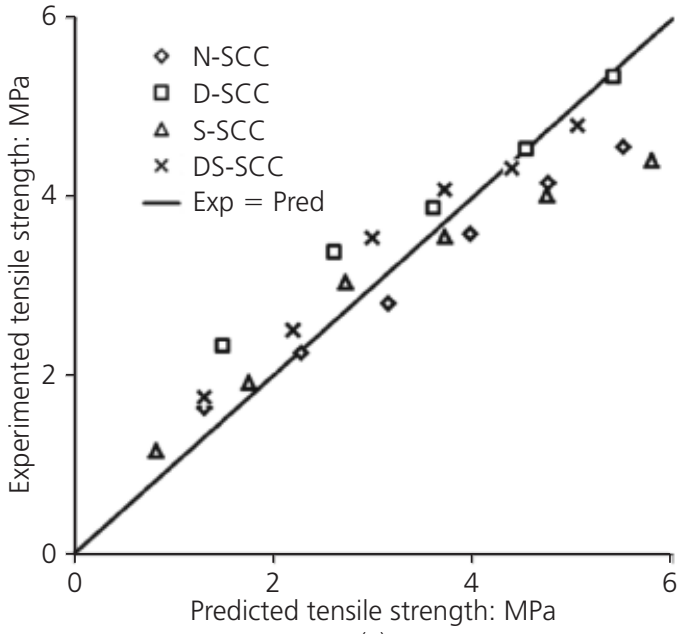

(a)

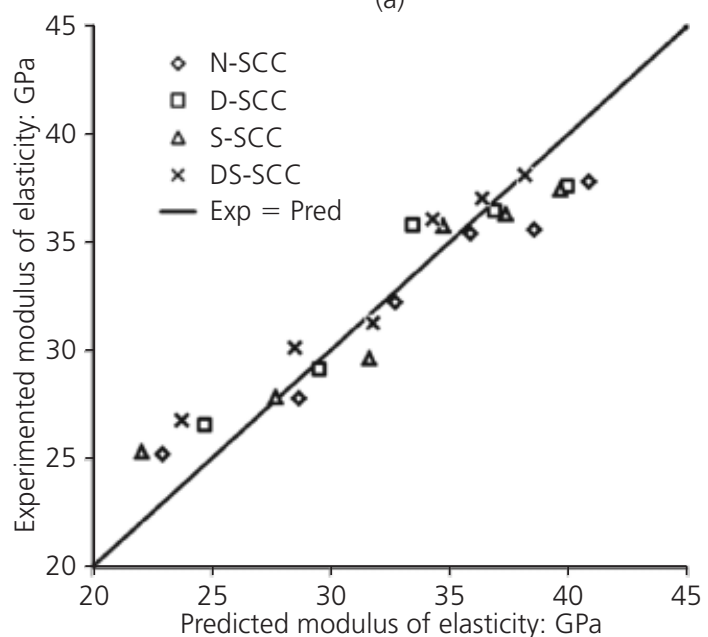

(b)

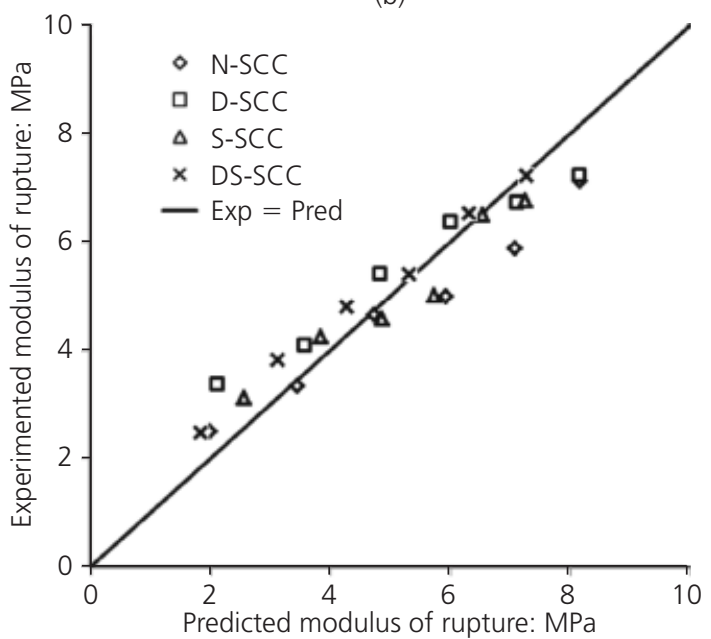

(c)

Figure 11. Predicted compressive strength-related mechanical properties values versus experimented values (a) tensile strength, (b) modulus of elasticity and (c) modulus of rupture. N-SCC, control SCC mixture; D-SCC, fibre-reinforced SCC (FRSCC) with steel fibres; S-SCC, FRSCC with polypropylene (PP) fibres; DS-SCC, FRSCC with hybrid steel and PP fibres 


\begin{tabular}{lllcc}
\hline Mix & $f_{\mathrm{ct}}$ & $f_{\mathrm{c}}^{\prime}$ & $\eta_{1}$ & $\eta_{2}$ \\
\hline N-SCC & $f_{\mathrm{ctN}}$ & $f_{\mathrm{cN}}^{\prime}$ & 0.204 & 0.8047 \\
D-SCC & $f_{\mathrm{ctfD}}$ & $f_{\mathrm{cfD}}^{\prime}$ & 0.237 & 0.7999 \\
S-SCC & $f_{\mathrm{ctfS}}$ & $f_{\text {cfS }}^{\prime}$ & 0.067 & 1.0889 \\
DS-SCC & $f_{\mathrm{ctfDS}}$ & $f_{\text {cfDS }}^{\prime}$ & 0.226 & 0.7585 \\
\hline
\end{tabular}

10. $n=n_{2}=n_{1}+(\rho+28 \times \omega)$ if $\varepsilon_{\mathrm{c}} \geqslant \varepsilon_{\mathrm{c}}^{\prime}$

11. $\rho=\left(135 \cdot 16-0 \cdot 1744 f_{\mathrm{c}}^{\prime}\right)^{-0 \cdot 46}$

N-SCC, control SCC mixture; D-SCC, fibre-reinforced SCC (FRSCC) with steel fibres; S-SCC, FRSCC with polypropylene (PP) fibres; DS-SCC, FRSCC with hybrid steel and PP fibres.

Table 14. Equation 5 constant components for different mixes

\begin{tabular}{lllrc}
\hline Mix & $E_{\mathrm{C}}$ & $f_{\mathrm{C}}^{\prime}$ & $\kappa_{1}$ & \multicolumn{1}{c}{$\kappa_{2}$} \\
\hline N-SCC & $E_{\mathrm{CN}}$ & $f_{\mathrm{CN}}^{\prime}$ & 10.913 & 0.3226 \\
D-SCC & $E_{\mathrm{CfD}}$ & $f_{\mathrm{cfD}}^{\prime}$ & 6.649 & 0.4383 \\
S-SCC & $E_{\mathrm{CfS}}$ & $f_{\mathrm{cfS}}^{\prime}$ & 10.395 & 0.3271 \\
DS-SCC & $E_{\mathrm{CfDS}}$ & $f_{\mathrm{cfDS}}^{\prime}$ & 12.895 & 0.2651 \\
\hline
\end{tabular}

$\mathrm{N}$-SCC, control SCC mixture; D-SCC, fibre-reinforced SCC (FRSCC) with steel fibres; S-SCC, FRSCC with polypropylene (PP) fibres; DS-SCC, FRSCC with hybrid steel and PP fibres.

Table 15. Equation 6 constant components for different mixes

\begin{tabular}{lllcc}
\hline Mix & $f_{\text {Cr }}$ & $f_{c}^{\prime}$ & $\delta_{1}$ & $\delta_{2}$ \\
\hline N-SCC & $f_{\text {CrN }}$ & $f_{\text {CN }}^{\prime}$ & 0.325 & 0.7871 \\
D-SCC & $f_{\text {crfD }}$ & $f_{\text {cfD }}^{\prime}$ & 0.376 & 0.7511 \\
S-SCC & $f_{\text {crfs }}$ & $f_{\text {cfS }}^{\prime}$ & 0.670 & 0.5818 \\
DS-SCC & $f_{\text {crfDS }}$ & $f_{\text {cfDS }}^{\prime}$ & 0.309 & 0.7714 \\
\hline
\end{tabular}

N-SCC, control SCC mixture; D-SCC, fibre-reinforced SCC (FRSCC) with steel fibres; S-SCC, FRSCC with polypropylene (PP) fibres; DS-SCC, FRSCC with hybrid steel and PP fibres.

\section{Table 16. Equation 7 constant components for different mixes}

typical 91-day age compressive stress-strain curve results are selected to compare with the proposed compressive stress-strain relationship.

$$
\frac{\sigma_{\mathrm{c}}}{f_{\mathrm{c}}^{\prime}}=\frac{n\left(\frac{\varepsilon_{\mathrm{c}}}{\varepsilon_{\mathrm{c}}^{\prime}}\right)}{n-1+\left(\frac{\varepsilon_{\mathrm{c}}}{\varepsilon_{\mathrm{c}}^{\prime}}\right)^{n}}
$$

9. $n=n_{1}=\left[1.02-1.17\left(E_{\mathrm{sec}} / E_{\mathrm{c}}\right)\right]^{-0 \cdot 74} \quad$ if $\varepsilon_{\mathrm{c}} \leqslant \varepsilon_{\mathrm{c}}^{\prime}$

\section{3. $E_{\mathrm{sec}}=f_{\mathrm{c}}^{\prime} / \varepsilon_{\mathrm{c}}^{\prime}$}

14. $\varepsilon_{\mathrm{c}}^{\prime}=\left(\frac{f_{\mathrm{c}}^{\prime}}{E_{\mathrm{c}}}\right)\left(\frac{v}{v-1}\right)$

15. $v=\frac{f_{\mathrm{c}}^{\prime}}{17}+0 \cdot 8$

where $\sigma_{\mathrm{c}}$ is concrete stress, $f_{\mathrm{c}}^{\prime}$ is the maximum compressive strength of concrete, $n$ is the material parameter that depends on the shape of the stress-strain curve, $\varepsilon$ is the concrete strain, $\varepsilon_{\mathrm{c}}^{\prime}$ is the strain corresponding with the maximum stress $f_{\mathrm{c}}^{\prime}, n_{1}$ is the modified material parameter at the ascending branch, $n_{2}$ is the modified material parameter at the descending branch, $E_{\mathrm{c}}$ is the modulus of elasticity, $E_{\mathrm{sec}}$ is the secant modulus of elasticity, $n_{1}$ is the modified material parameter at the ascending branch, $n_{2}$ is the modified material parameter at the descending branch and $\rho, \omega$ are the coefficients of linear equation.

\section{Conclusions}

The following conclusions can be drawn from this study.

- A novel experimental program was performed. Four different SCC mixes were used in the experiment. These mixes include N-SCC, D-SCC, S-SCC and DS-SCC.

- The compressive strength, tensile strength, modulus of elasticity, modulus of rupture and compressive stress-strain curve are tested at ages of 3, 7, 14, 28, 56 and 91 days. These properties' differences between SCC mixes show that these differences decrease with time.

- The average compressive strength of the DS-SCC mix is higher than that of the N-SCC, D-SCC and S-SCC mixes respectively. The results indicate that compressive strength of the DS-SCC mix at 91 days is $10 \cdot 71 \%, 1 \cdot 62 \%$ and $8 \cdot 32 \%$ higher than that of the N-SCC, D-SCC and S-SCC mixes respectively.

- The average tensile strength of the D-SCC mix is higher than that of the DS-SCC, N-SCC and S-SCC mixes respectively. The results show that the tensile strength of D-SCC mix at 91 
Mechanical characteristics of selfcompacting concrete with and without

fibres

Aslani and Nejadi

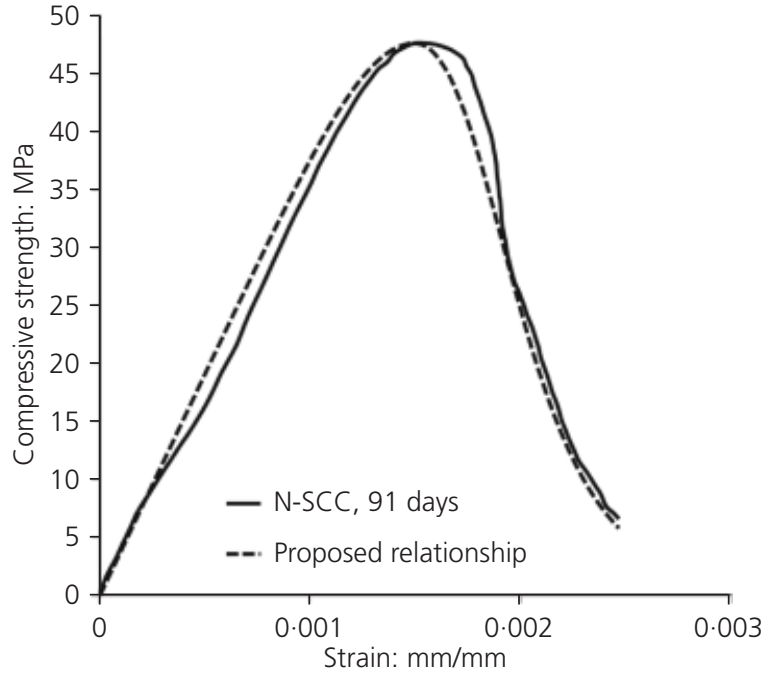

(a)

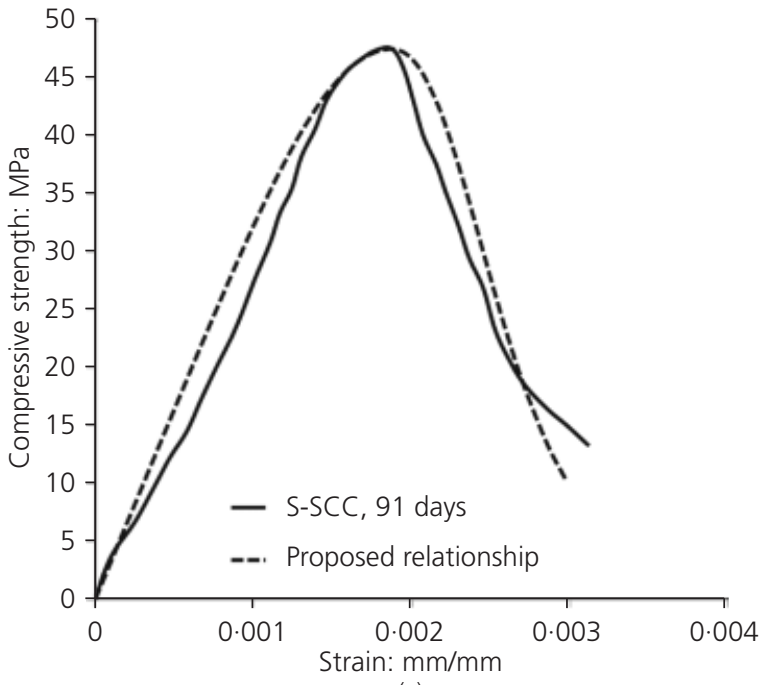

(c)

Figure 12. Comparison between experimented compressive stress-strain curve result with proposed relationship (a) control self-compacting concrete $(\mathrm{SCC})$ mixture $(\mathrm{N}-\mathrm{SCC})$, (b) fibrereinforced SCC (FRSCC) containing steel fibres (D-SCC),

(c) FRSCC containing polypropylene (PP) fibres (S-SCC) and

(d) FRSCC containing hybrid steel and PP fibres (DS-SCC)

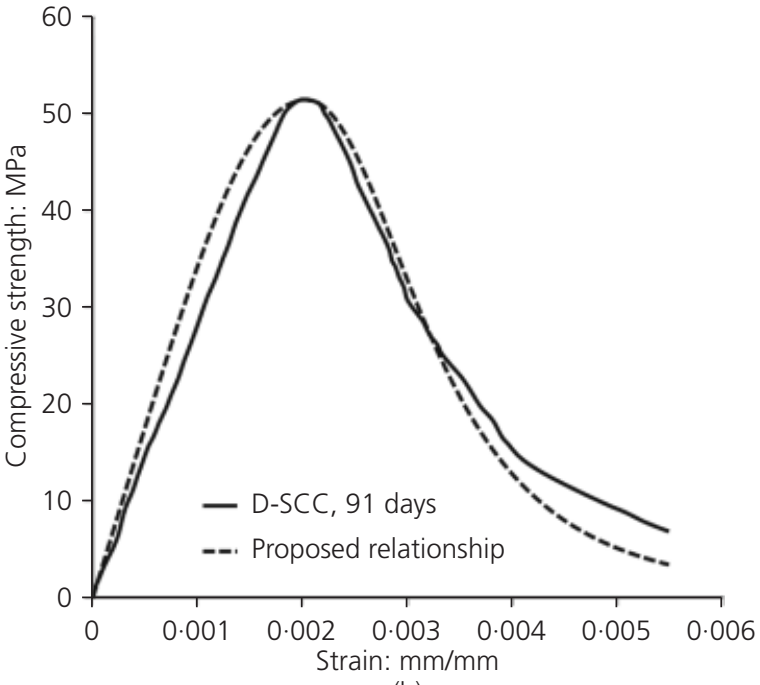

(b)

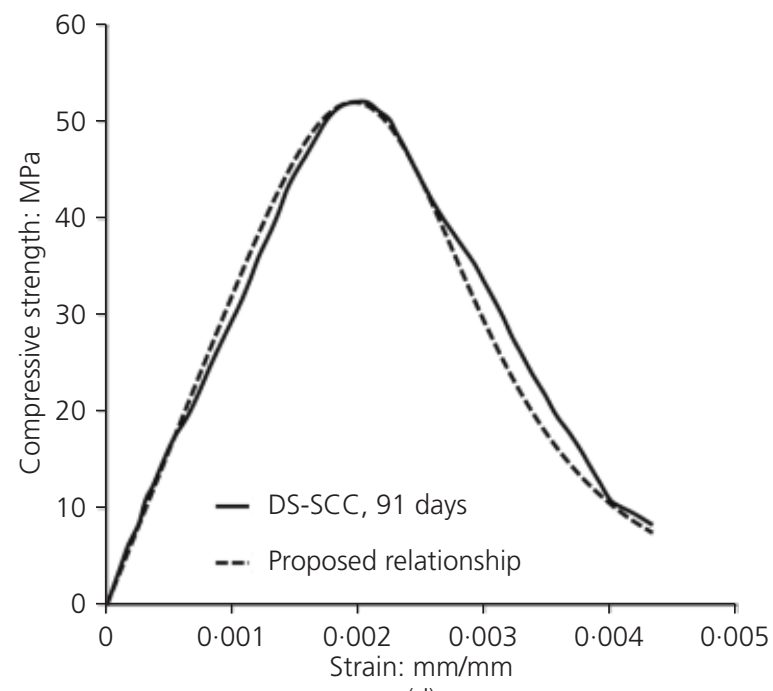

(d) days is $15.95 \%, 18.89 \%$ and $11 \cdot 76 \%$ higher than that of the N-SCC, S-SCC and DS-SCC mixes respectively.

- The average modulus of elasticity of the DS-SCC mix is higher than that of the N-SCC, D-SCC and S-SCC mixes respectively. Additionally, the results indicate that tensile strength of the DS-SCC mix at 91 days is $0 \cdot 86 \%, 1 \cdot 41 \%$ and $1.72 \%$ higher than that of the N-SCC, D-SCC and S-SCC mixes respectively.

- The average modulus of rupture of the D-SCC mix is higher than that of the N-SCC, S-SCC and DS-SCC mixes respectively. Also, the results indicate that the modulus of rupture of the D-SCC mix at 91 days is $1 \cdot 30 \%, 6 \cdot 44 \%$ and $0 \cdot 21 \%$ higher than that of the N-SCC, S-SCC and DS-SCC mixes respectively.

- Analytical expressions to predict the most significant mechanical properties (i.e., compressive strength, tensile strength, modulus of elasticity and modulus of rupture) of the developed SCC mixes at an age $t$ were presented.

- Analytical relationships to calculate the tensile strength, modulus of elasticity and modulus of rupture of the SCC mixes related to compressive strength were proposed. 
- A compressive stress-strain relationship was proposed to model the behavior of the SCC mixes from an early age. This relationship was capable of modelling the complete compressive behavior of normal SCC and FRSCC with high accuracy.

\section{Acknowledgements}

This work was supported by Centre for Built Infrastructure Research, School of Civil and Environmental Engineering, University of Technology Sydney, Australia. The authors would like to express their sincere gratitude and appreciation to Boral, BOSFA and Concrite companies.

\section{REFERENCES}

ACI (1999) ACI544.2R: State-of-the-art report on fiber reinforced concrete. Technical report. ACI, Farmington Hills, MI, USA.

ACI (2007) ACI Committee 237: 237R-07. Self-consolidating concrete. American Concrete Institute, Farmington Hills, MI, USA.

Aslani F and Nejadi S (2012a) Mechanical properties of conventional and self-compacting concrete: An analytical study. Construction Building Materials 36: 330-347.

Aslani F and Nejadi S (2012b) Bond characteristics of steel fibre reinforced self-compacting concrete. Canadian Journal of Civil Engineering 39(7): 834-848.

Aslani F and Nejadi S (2012c) Bond behaviour of reinforcement in conventional and self-compacting concrete. Advances in Structural Engineering 15(12): 2033-2051.

Aslani F and Nejadi S (2012d) Shrinkage behaviour of selfcompacting concrete. Journal of Zhejiang University SCIENCE A 13(6): 407-419.

ASTM (2000) Annual Book of ASTM Standards 2000. Volume 04.02, Concrete and Aggregates. ASTM International, West Conshohocken, PA, USA.

Balaguru PN and Shah SP (1992) Fiber Reinforced Cement Composites. McGraw-Hill, New York, USA.

Bui VK, Shah SP, Geiker MR (2003) Rheology of Fiber-Reinforced Cementitious Materials. RILEM PRO30 High Performance Fibre Reinforced Composites HPFRCC4. Reunion Internationale des Laboratoires et Experts des Materiaux, Systemes de Construction et Ouvrages, Bagneux, France, pp. 221-232.

Busterud L, Johansen K and Døssland ÅL (2005) Production of Fiber Reinforced SCC. SCC 2005, Session C-3: FiberReinforced SCC.

Corinaldesi V and Moriconi G (2004) Durable fiber reinforced self-compacting concrete. Cement and Concrete Research 34(2): 249-254.

Cunha V (2006) Compression behaviour of steel fibre reinforced self-compacting concrete - age influence and modelling. Report 06-DEC/E-04, University of Minho, Portugal.

EFNARC (2005) The European Guidelines for Self-Compacting Concrete, Specification, Production and Use. Experts for Specialised Construction and Concrete Systems, Farnham, UK. Groth P and Nemegeer D (1999) The use of steel fibres in self- compacting concrete. In Proceedings of the First International RILEM Symposium on Compacting Concrete, Stockholm, Sweden (Skarendahl А and Petersson Ö (eds)), pp. 497-507.

Grünewald S (2006) Performance-based Design of SelfCompacting Fibre Reinforced Concrete. $\mathrm{PhD}$ thesis, Delft University of Technology, Delft, the Netherlands.

Grünewald S and Walraven JC (2001) Parameter-study on the influence of steel fibers and coarse aggregate content on the fresh properties of self-consolidating concrete. Cement and Concrete Research 31(12): 1793-1798.

Khayat KH and Roussel Y (1999) Testing and performance of fiber-reinforced, self-consolidating concrete. In Proceedings of Symposium on Self-compacting Concrete. Stockholm, Sweden (Skarendahl A (ed.)), pp. 509-521.

Liao WC, Chao SH, Park SY and Naaman AE (2006) SelfConsolidating High Performance Fiber Reinforced Concrete (SCHPFRC) - Preliminary Investigation. Report UMCEE 06-02, Department of Civil and Environmental Engineering University of Michigan Ann Arbor, USA, p. 68.

Massicotte B, Degrange G and Dzeletovic N (2000) Mix Design for SFRC Bridge Deck Construction. RILEM PRO15 FibreReinforced Concrete BEFIB. RILEM, Bagneux, France, pp. $119-128$.

RTA (Regional Transportation Authority) (2006) Materials Test Methods, vol. 1. RTA, Chicago, IL, USA.

SA (Standards Australia) (1991) AS1012.14: Method for securing and testing from hardened concrete for compressive strength. Standards Australia, Sydney, Australia.

SA (1997) AS1012.17: Determination of the static chord modulus of elasticity and Poisson's ratio of concrete specimens. Standards Australia, Sydney, Australia.

SA (1998) AS3583: Methods of test for supplementary cementitious materials for use with Portland cement. Standards Australia, Sydney, Australia.

SA (2000a) AS1012.10: Determination of indirect tensile strength of concrete cylinders. Standards Australia, Sydney, Australia.

SA (2000b) AS1012.11: Determination of modulus of rupture. Standards Australia, Sydney, Australia.

SA (2000c) AS1478.1: Chemical admixtures for concrete, mortar and grout - Admixtures for concrete. Standards Australia, Sydney, Australia.

SA (2001) AS3582.2: Supplementary cementitious materials for use with Portland and blended cement - slag - ground granulated iron blast-furnace. Standards Australia, Sydney, Australia.

SA (2006) AS2350: Methods of testing Portland and blended cements. Standards Australia, Sydney, Australia.

SA (2010) AS3972: General purpose and blended cements. Standards Australia, Sydney, Australia.

SA (2011) AS1141: Methods for sampling and testing aggregates - Particle size distribution - Sieving method. Standards Australia, Sydney, Australia.

Sahmaran M and Yaman IO (2007) Hybrid fiber reinforced selfcompacting concrete with a high-volume coarse fly ash. Construction and Building Materials 21(1): 150-156. 
Magazine of Concrete Research Volume 65 Issue 10
Mechanical characteristics of self-

compacting concrete with and without

fibres

Aslani and Nejadi
Sahmaran M, Yurtseven A and Yaman IO (2005) Workability of hybrid fiber reinforced self-compacting. Building and Environment 40(12): 1672-1677.
Schumacher P (2008) Rotation Capacity of Self-Compacting Steel Fiber Reinforced Concrete. PhD thesis, Delft University of Technology, Delft, the Netherlands.

\section{WHAT DO YOU THINK?}

To discuss this paper, please submit up to 500 words to the editor at www.editorialmanager.com/macr by 1 November 2013. Your contribution will be forwarded to the author(s) for a reply and, if considered appropriate by the editorial panel, will be published as a discussion in a future issue of the journal. 